\title{
Resources
}

Rules of the Game: Resources for Researching Pacific Islands Sport

D KEALI'I MACKENZIE

The Contemporary Pacific, Volume 26, Number 2, 447-456

(C) 2014 by University of Hawai'i Press 


\section{Rules of the Game: Resources for \\ Researching Pacific Islands Sport}

\section{Keali i MacKenzie}

Researching sport in the Pacific Islands, or Pacific Islanders in sportstwo overlapping perspectives-requires the foresight to think a little bit outside the box. As the articles in this issue attest, writing about sport and its role in the Pacific asks researchers to bring their work into an increasingly multi- and interdisciplinary realm. It is not enough to just focus on sport itself: One must also consider sport as part of global flows and interactions, as semiotics, as a path for migration and social mobility. Given the variability of the topic and its broad range, it is unsurprising that information resources are distributed across a wide plane.

The purpose of this resources essay is not so much to point to what is already out there as to provide tools for conducting research on these interrelated topics. Subscription databases such as Ebscohost's Academic Search Premier and LexisNexis Academic can be rich resources. ${ }^{1}$ Google Scholar, a "quasi-subscription" database in that it is available on the open Internet but returns a mix of pay-to-view and free material, can also be valuable. In addition, World Cat, the international online library catalog, is helpful for finding a wide range of publications that exist in libraries around the globe. ${ }^{2}$ These are some of the "big league" names in terms of research, but they are by no means the only sources of information on the subject, and not all researchers have access to them. Therefore, the remainder of this essay, which explores search strategies, dissertations and theses, and the role of popular magazines and social media, includes free databases as well.

\section{Search Strategies}

For many researchers, finding the right combination of search terms is one of the more difficult tasks: No matter how well one knows a subject, mul-

The Contemporary Pacific, Volume 26, Number 2, 448-456

(C) 2014 by University of Hawai' $i$ Press 
tiple words and phrases are needed to access relevant articles and information on any given topic. Database creators and librarians have their own specialized terminology, which may seem inscrutable to researchers outside of the profession but which is (ironically or not) useful for facilitating discovery of and access to material in their collections.

Below are some strategies and search terms related to sports in the Pacific. These terms may be used in academic databases and online library catalogs.

\section{Boolean Operators}

Boolean operators are a common feature of most—though not all—scholarly databases and can help a researcher define the relationship between search phrases or search terms.

- AND is used to narrow a search by finding all terms in a document. Example: sport AND Tonga

- OR is used to expand a search by finding any term in a document. Example: Vanuatu OR Tonga

- Parentheses are used to group terms, phrases, or ideas together. Example: (rugby OR football) AND (Tonga AND Samoa)

In the particular case of Google Scholar, Boolean operators can occasionally be useful in helping to somewhat refine what can otherwise be messy keyword searches of the open Internet. For instance, if one is broadly looking for articles on a particular sport but across diverse geographies or ethnicities, a Boolean search of (Rugby AND (Samoa OR Samoans OR Tonga OR Tongans OR Fiji OR Fijians)) will at once broaden and refine the search results to yield, among others:

Besnier, Niko. 2002. The Athlete's Body and the Global Condition: Tongan Rugby Players in Japan. American Ethnologist 39 (3): 49 I-5 IO.

Hammond, Joyce D. I998. Visualizing Themselves: Tongan Videography in Utah I. Visual Anthropology I (4): 379-400.

In cases in which spelling conventions have changed over time or are not fully agreed on, or in which misspellings are themselves common, Boolean operators can also be useful in finding all possible variations of a word. Examples: 
(Chamorro OR Chammorro OR Chamoru) AND sport

(Fiji OR Viti) AND Rugby

\section{Wildcard Symbols}

These symbols allow a search to be expanded and can be a powerful tool in finding relevant documents. Each database and online library catalog has its own wildcards, but the two most common are the asterisk (*) and question mark (?). Each is used to expand a search through truncation: By placing one of these symbols at the end of a word, the search is broadened to include all possible variations of the root word. For example, Tonga* will bring up results with the words Tonga, Tongan, Tongans, Tongatapu, and so forth. Wildcards can also be combined with Boolean operators, for example:

(Tonga* OR Samoa*) AND sport

(Pacific AND Island*) AND rugby

\section{Citations}

One of the more useful ways to find materials on a given subject is through a citation count search, which involves using an academic database to find out how many times an article has been cited by other scholars and by whom. This citation function is becoming increasingly common, though the best-known examples are Google Scholar and Web of Knowledge (the latter being a subscription database maintained by Thomson Reuters). In both cases, one need only type in the name of an author, or title of a work, and in each of the results listed there is a hyperlink titled "Cited by," followed by the number of citations. By clicking on this hyperlink, one can see the different articles, books (at least in Google Scholar), and sometimes theses or dissertations that cite a particular work. By tracking how often works are cited and by whom, one can not only find related works on a subject but also begin to map out a body of scholarship as it unfolds over time.

A note of caution, however: In the past, Google Scholar was known to have inflated its author citation counts, ${ }^{3}$ and a comparison of citation counts between Web of Knowledge and Google Scholar may turn up large discrepancies.

As an example, in January 20I4, Brendan Hokowhitu's 2004 article 
"Tackling Maori Masculinity: A Colonial Genealogy of Savagery and Sport" (The Contemporary Pacific I6:259-284) received a citation count of twenty-seven in Web of Science and eighty in Google Scholar. There are many reasons for this, including what kinds of databases these are, what disciplines they index, and even human error. While citation counts may at times provide an unclear assessment of such things as academic impact factor, they are nonetheless a very effective way of visualizing the shape of a scholarly discourse.

\section{Subject Headings}

Library of Congress (LC) subject headings are another way to search for relevant materials. Used internationally in online library catalogs, these headings are applied to individual library cataloging records in order to index and arrange materials by subject. LC subject headings (or LCSHS) are a type of "controlled vocabulary," which may make them seem arcane or dense to non-librarians: Use the wrong term, or the right terms in the wrong order, and in most cases you will return zero results-and, unlike popular web-search engines, most online library catalogs do not include a "did you mean" feature to automatically correct spelling or grammar errors. LCSHs are not always intuitive, and certain individual headings have been in use for many decades. Thus they may contain biases and reflect outdated points of view. ${ }^{4}$ Even so, LCSHs are a common feature of many library catalogs around the globe (as well as in the global library catalog WorldCat) and, when used properly, can be a powerful tool.

To explain the various intricacies of LCSH-controlled vocabulary is beyond the scope of this article, but very generally speaking, LC subject headings as they relate to sport in the Pacific will be composed of a topic (eg, "sports" or "rugby football") and a geography or people (eg, "Fiji" or "Samoans"). Other terms ("history," "periodicals," etc) are then added to further narrow search results.

Listed below is a sample of subject headings from the University of Hawai'i-Mānoa Library's online catalog, Voyager:

Feminism and sports-Tonga.

Maori (New Zealand people)-Sports.

Pacific Islander Americans-Sports-History.

Papua New Guinea. National Sports Institute-Periodicals.

Rugby football-Fiji. 
A more complete listing of Pacific-related LC subject headings has been compiled by the Hawai'i Library Association and is available online courtesy of the Chaminade University website. This online list does not include general subject headings (such as "sports" or "cricket" or "rugby football") but is nonetheless helpful in determining proper terminology for Pacific-specific headings (the use of "Samoan Islands" as opposed to "Samoa," for instance.)

\section{Dissertations And Theses}

Dissertations and theses present another important site of scholarship on sports in the Pacific. Free databases such as Google Scholar are increasingly returning either citations of or full-text links to dissertations and theses. The subscription database ProQuest Dissertations and Theses Abstracts also does a somewhat global search of dissertations and theses.

For both of these databases, the search strategies listed above will help researchers yield interesting results. Below are two results from a Dissertation and Theses Abstracts search for (Melanesia* OR Micronesia* OR Polynesia* or Maori) AND (sport* OR football OR rugby OR soccer):

Markham, Jesse Makani. 2008. An Evolving Geography of Sport: The Recruitment and Mobility of Samoan College Football Players I9982006. MA thesis, University of Hawai'i at Mānoa.

Goris, Michelle. 2013. Adidas, the All Blacks, and Maori Culture: Globalization and the Reformation of Local Identities. PhD dissertation, University of Oregon.

While Dissertations and Theses Abstracts is a paid database, those without institutional affiliation (or who are at an institution that doesn't subscribe to Proquest) can still search its database for citations via Dissertation Express, which allows users to see basic bibliographic information (title, author, institution, date) but not abstracts or full text. Proquest also recently launched PQDT Open, which searches for the subset of freely available online dissertations and theses within its larger database. There are, however, several other search engines that will generally provide better coverage of Pacific-specific theses and dissertations online, among 
them the National Library of Australia's Trove and the National Library of New Zealand's Kiwi Research Information Service. ${ }^{5}$

\section{The Role of Popular Magazines and Social Media}

Popular magazines from the region such as Mana: The Maori Magazine for Everyone, Spacifik: Pacific and Maori Proud, and Fiji Islands Business, to name but a few, paint a different picture than academic work and are a rich source of information about sporting trends, individual teams, and individual players.

This class of publication also presents an opportunity to study the media image of Pacific people in sports. For instance, recent issues of Hana Hou! (the in-flight magazine of Hawaiian Airlines) have included articles about Samoans in the National Football League (Simon 2007) and Canadian Football League player Chad Owens (Kandell 2013), the latter of which included images of Owens displaying his Polynesian tattoos. Spacifik frequently contains photographs of sports players and teams, while advertisements in these and similar magazines are another area ripe for analysis.

Finding articles in popular magazines can be challenging. The Hawai' $\mathrm{i}-$ Pacific Journal Index (HPJI), an open-access database created and maintained by the University of Hawai'i-Mānoa Library, indexes the contents of approximately I 30 academic journals and popular press titles, among the latter being Mana, Spacifik, Fiji Islands Business, Tahiti Pacifique, and Hana Hou! ${ }^{6}$ In addition to the indexing provided by the HPJI, the openaccess Pacific Islands Report, published online by the East-West Center's Pacific Islands Development Program, serves as a news aggregator, republishing a variety of articles (including those related to sport) from news outlets throughout the region. In that sense, Pacific Islands Report can be used as a partial index to news outlets of the region.

Along with the popular press, social media is a potential avenue for information and research about sporting in the Pacific or participation of Pacific Islanders. Many athletes have their own Facebook, Instagram, or Twitter accounts, which can provide firsthand insight into sports and the lives of athletes. For example, New Zealand Women's Sevens player Linda Itunu is on Twitter; Cincinnati Bengals defensive tackle Domata Peko is on Twitter and Instagram; and Pittsburgh Steelers strong safety Troy Polamalu is on all three. As with the open Internet, social media sites can also 
lead to serendipitous first mentions of previously unknown people, events, or organizations, any of which can later be followed up with more traditional academic research. For example, a search for Troy Polamalu on Twitter brings up among the results an account of the establishment of the Polynesian Football Hall of Fame.

Social media not only gives access to individual athletes and sporting associations but also allows a researcher to more directly see what people are saying about sports and athletes. Although Twitter limits individual posts to a maximum of $\mathrm{I} 4 \mathrm{O}$ characters, as a "microblog" it also allows users to share links to pictures, videos, articles, and websites. Instagram (which is primarily a photo-sharing site) allows registered users to comment on photos posted by other users; in the case of athletes and sports, these comment fields are sites of rich debate among sports fans, with occasional back and forth between fans and athletes themselves.

Searching within social media presents its own set of challenges. Twitter and Instagram use the hashtag (\#) symbol as a way of tagging words, phrases, and images, with tags being applied by the users themselves. For example, searching for \#fijirugby on Twitter brings up "tweets" from the Fiji Rugby Union as well as those from users talking about different aspects of rugby in Fiji. Clicking on a hashtagged phrase will bring up other posts that make use of the same hashtag. A \# can also indicate a larger linked discussion on a particular topic.

In addition to the challenges of searching within social media, there remains the question of how best to integrate these materials into traditional academic research. Such research should be made with a clear set of goals, because while there is great potential in social media, the sheer volume can be overwhelming. It can also be ephemeral: There is a constant flux of information due to users' ability to delete posts and comments at will, which in turn creates challenges in citing and documenting sources in such a way that they will remain available to future researchers. Nonetheless, the social media landscape remains a vast site for potential scholarship.

Ultimately, research on Pacific sport has many potential avenues and paths to explore. I hope this essay can serve as a beginning "playbook" for those who wish to continue in this area of research-along with the collected articles (and their attendant bibliographies) in this special issue. In the end, understanding who has written on different aspects of this topic is just as vital to the project as knowing where to look for them. 
Notes

I The web addresses (URLS) for all databases and websites mentioned in this essay are listed in appendix I. In the case of subscription databases, URLs for each database publisher's informational pages are provided.

2 WorldCat recently launched an open-access version of its online catalog (see appendix I for URL); while this free version can be extremely useful for researchers, it remains far less robust than the paid database.

3 For detailed critiques of Google Scholar, Web of Science, and other scholarly databases as they relate to citation counts, see Jacso 20I 2a, 20I 2b, and 2007.

4 It should also be noted that not all LC subject headings are written in stone. In recent years, catalogers at the University of Hawai'i-Mānoa Library, led by now-retired librarian Ruth Horie, successfully petitioned the Library of Congress to change the subject heading "Hawaii-History-Revolution of 1893 " to "Hawaii-History-Overthrow of the Monarchy, 1893 " in an attempt to more accurately reflect those events.

5 For more on finding Pacific-related dissertations and theses, see Dawrs 20 I 2.

6 In the cases of Mana and Spacifik, indexing in the Hawai'i-Pacific Journal Index began in March 20I4; over time, earlier issues will also be indexed (all other magazine titles mentioned in this section have been indexed from volume I, issue I). Because of the widely varying layout and editorial content in popular press titles, many are only indexed selectively in the HPJ. For example, in the case of Spacifik, only cover, "feature," and sports articles are indexed. For more on searching in the HPJI, see Peacock I993; Dawrs 20 II.

\section{References}

Dawrs, Stuart

20I I Uнм Hawai'i Pacific Journal Index: An Unsung Resource. Pacific News from Mānoa, April-June: 3 .

2OI2 Virtually There: Open Access and the Online Growth of Pacific Dissertations and Theses. The Contemporary Pacific 24:347-357.

Jacso, Peter

20I 2a Grim Tales about the Impact Factor and the H-Index in the Web of Science and the Journal Citation Reports Databases: Reflections on Vanclay's Criticism. Scientometrics 92 (2): 325-354.

20I2b Using Google Scholar for Journal Impact Factors and the H-Index in Nationwide Publishing Assessments in Academia: Siren Songs and Air-Raid Sirens. Online Information Review 36 (3): 462-478.

2007 Google Scholar Revisited. Online Information Review 32 (I): IO2II 4 . 
Kandell, Aaron

2013 The Fighter: Hawai'i's Chad Owens Became the Greatest Player in the CFL the Same Way He's Accomplished Everything: By Never Giving Up. Hana Hou! The Magazine of Hawaiian Airlines I6 (5):

Peacock, Karen M I23-I 29.

I993 Indexing the Islands: Creating a Pacific Periodical Database. The Contemporary Pacific 5:432-435.

Simon, Liza

2007 Motu Football: Samoans Go Deep in the NFL. Hana Hou! Io (6): 66-79, IOI. 


\section{Appendix i: Research Websites and Subscription or Open-Access Databases}

\begin{tabular}{|c|c|c|}
\hline Website & Host & URL \\
\hline $\begin{array}{l}\text { Academic Search } \\
\text { Premier }\end{array}$ & EbscoHost & $\begin{array}{l}\text { http://www.ebscohost.com/academic/ } \\
\text { academic-search-premier }\end{array}$ \\
\hline $\begin{array}{l}\text { Dissertations and } \\
\text { Theses Abstracts }\end{array}$ & ProQuest & $\begin{array}{l}\text { http://www.proquest.com/products-services/ } \\
\text { dissertations/ }\end{array}$ \\
\hline Dissertation Express & ProQuest & http://dissexpress.umi.com/dxweb/search.html \\
\hline Google Scholar & Google & http://scholar.google.com \\
\hline $\begin{array}{l}\text { Hawai'i-Pacific } \\
\text { Journal Index }\end{array}$ & $\begin{array}{l}\text { University of } \\
\text { Hawai'i- } \\
\text { Mānoa Library }\end{array}$ & http://hpji.lib.hawaii.edu/ \\
\hline $\begin{array}{l}\text { Kiwi Research } \\
\text { Information Service }\end{array}$ & $\begin{array}{l}\text { National Library } \\
\text { of New Zealand }\end{array}$ & http://nzresearch.org.nz \\
\hline $\begin{array}{l}\text { LexisNexis } \\
\text { Academic }\end{array}$ & LexisNexis & $\begin{array}{l}\text { http://www.lexisnexis.com/hottopics/ } \\
\text { lnacademic/? }\end{array}$ \\
\hline Pacific Islands Report & East-West Center & http://pidp.eastwestcenter.org/pireport/ \\
\hline $\begin{array}{l}\text { Library of Congress } \\
\text { Subject Headings for } \\
\text { the Pacific Islands }\end{array}$ & $\begin{array}{l}\text { Chaminade } \\
\text { University }\end{array}$ & $\begin{array}{l}\text { http://hla.chaminade.edu/resources/ } \\
\text { PacLCSHupdate.pdf }\end{array}$ \\
\hline PQDT Open & ProQuest & http://pqdtopen.proquest.com/search.html \\
\hline Trove & $\begin{array}{l}\text { National Library } \\
\text { of Australia }\end{array}$ & http://trove.nla.gov.au \\
\hline $\begin{array}{l}\text { Voyager Online } \\
\text { Catalog }\end{array}$ & $\begin{array}{l}\text { University of } \\
\text { Hawai'i- } \\
\text { Mānoa Library }\end{array}$ & $\begin{array}{l}\text { http://uhmanoa.lib.hawaii.edu:7008/vwebv/ } \\
\text { searchBasic?sk=manoa }\end{array}$ \\
\hline Worldcat & $\begin{array}{l}\text { Online Computer } \\
\text { Library Center, Inc }\end{array}$ & http://www.worldcat.org/ \\
\hline
\end{tabular}

